\title{
NECESSIDADE DE ORIENTAÇÃo À SAÚdE DO PACIENTE BIABETICO
}

\author{
* Solange Maria Ramos
}

\begin{tabular}{l|l|}
\hline RBEn/04 \\
\hline
\end{tabular}

RAMOS, S.M. - Necessidade de orientaçāo à saúde do paciente diabético. Rev. Bras. Ene.; DF, 29 : 38-41, 1976.

\section{INTRODUÇÃO:}

A orientação para a saúde consiste no conjunto de ensinamentos que visam à mudança de atitudes, de comportamento, e o desenvolvimento de habilidades úteis à promoção, à manutenção e à recuperação da saúde.

Assim, a orientação para a saúde é de particular importância para o paciente diabético, uma vez que esse necessita de cuidados especificos, imprescindíveis à sua segurança física, emocional e social.

A ingestão de uma dieta adequada, a verificação regular da glicosúria, da glicemia, e outros cuidados igualmente voltados para a manutenção do controle do equilíbrio do paciente diabético, asseguram-lhe uma vida normal, participante nas atividades diárias, livre das possíveis complicaçōes dessa deficiência. Essa participação efetiva na escola, no trabalho e nos esportes leva à modificação do conceito do diabetes na sociedade.
Na situação do paciente dependente do uso diário de insulina, a dificuldade de aprendizagem aumenta na razāo inversa do seu grau de instrução.

Levando-se em consideração as dificuldades de algumas estudantes de enfermagem para a aprendizagem dos cálculos para a dosagem de insulina nas diversas concentraçōes, compreende-se a necessidade de programação e avaliação do ensino que deve ser continuamente oferecido a sucessivos grupos de pacientes.

Outros fatores como a idade, a acuidade visual e a condição social influenciam a aprendizagem e devem ser levados em consideração pelos responsáveis por esses programas de orientação.

A participação no ensino ao paciente, dentro das possibilidades de cada um, é função de todos aqueles que 0 assistem. A enfermeira, como líder da equipe de enfermagem, e como coordenadora da assistência de enfermagem prestada ao

- Professora Assistente do Departamento de Enfermagem Fundamental da Escola de Enfermagem da UFRJ. 
RAMOS, S.M. - Necessidade de orientação à saúde do paciente diabético. Rev. Bras.

Enf.; DF, 29 : 38-41, 1976.

paciente, assume um papel de importância decisiva nesse programa.

Há portanto três aspectos a serem considerados na orientação para a saúde: a necessidade que todo indivíduo tem de preservar sua saúde, a valorização dessa necessidade no caso de diabético, pelas implicaçōes da doença, e uma tomada de consciência por parte da enfermeira, no sentido de assumir o ensino do paciente, como parte integrante de suas funçōes, inserindo-o na própria assistência de enfermagem. O problema é que há uma evidência do desempenho dessa função: observam-se idas e vindas constantes de pacientes diabéticos a unidades de internação, cada vez em situação mais precária, em vista do cuidado irregular e deficiente que $o$ paciente se dispensa ou recebe de algum membro da família.

\subsection{RECENTES DISCUSSOES DO PROBLEMA NO NOSSO MEIO}

ARDUINO, 1973 (1), aconselha que a instrução do paciente deve ser iniciada a partir da primeira consulta médica, o que, de certo modo, contribui para o ajustamento do paciente à sua condição de diabético. Acrescenta que não é possível que se exija a efetiva cooperação do paciente, se ele desconhece, não sabe como fazer para corresponder à expectativa da equipe de saúde quanto ao seu desempenho e se, inclusive, desconhece as possiveis consequências de sua omissão.

MENDES, 1975 (2), relata, após pesquisa realizada em domicílio de pacientes diabéticos, em Ribeirão Preto, haver constatado que esses cometiam erros desde a aquisição do produto na farmácia, em relação ao que lhe fora prescrito, situação que se agravava durante o preparo da dose indicada. Embora esses pacientes tivessem afirmado, durante a entrevista no ambulatório, que sabiam adquirir, preparar e administrar a insuli- na, conforme a prescrição médica, ao observá-los no desempenho dessas atividades, concluiu que dos cinquenta visitados apenas dois (4\%) haviam agido corretamente.

RAMOS, 1975 (3), em estudo realizado em sete hospitais gerais e especializados em diabetes, revela que há um comprovado interesse por parte dos pacientes em receber informaçōes sobre a origem, o tratamento, o prognóstico e os prováveis prejuízos físicos e/ou sociais dessa deficiência orgânica. Acrescenta que as enfermeiras responsáveis pela assistência desses pacientes estāo conscientizadas da importância de suprir essa necessidade de aprendizagem por eles revelada. Ocorre que o desenvolvimento da assistência a esse problema de enfermagem, identificado em um grupo comum de pacientes, revelou-se falho, não sendo encontrados registros de prescriçōes de enfermagem visando a solução desse problema, e as unidades que desenvolviam esse tipo de assistência revelaram deficiência, ora por atingirem apenas a um grupo previamente selecionado, ora por não haver um planejamento, uma meto dologia própria, ou ainda uma avaliação devidamente registrada para estudos posteriores.

\subsection{OBJETIVOS}

Em relação às enfermeiras foram determinados os seguintes objetivos:

- Verificar se as enfermeiras diretamente responsáveis pela assistência de enfermagem aos pacientes estão integrando atividades de orientação para a saúde nessa assistência.

- Determinar a participação da enfermeira nos programas de orientação dos pacientes diabéticos.

- Verificar se após a orientação é feita a avaliação da aprendizagem dos pacientes. 
RAMOS, S.M. - Necessidade de orientaçăo a saúde do paciente diabético. Rev. Bra.

Ens.; DF, 29 : 38-41, 1976.

Fim relação aos pacientes:

- Verificar quem os pacientes percebem como participantes da orientação para o seu autoculdado.

\section{METODOLOGIA:}

O estudo fol reallzado em onze unidades de clínica médica e especlalizada em diabetes. Foram utilizados dols tipos de questionário, um para pacientes e outro para efermeiras(os).

$O$ dos pacientes fol preenchido durante entrevistas com 36 deles. A escolha recalu sobre aqueles encontrados nas enfermarlas ou nos ambulatórios, nos dias do levantamento de dados. Quanto ao questionário das(OS) enfermelras(os), foram distribuídos entre os(as) chefes dessas Unidades, respectivas supervisoras e substitutas eventuais, perfazendo o total de quatorze os que nos foram devolvidos.

\section{RESULTADOS}

Entre as enfermeiras respondentes verifica-se que 10 (71,5\% da amostra) eram chefes das Unidades estudadas, e $4(28,5 \%)$, supervisoras das mesmas. Esses dados revelaram-se importantes por coresponderem ao objetivo do trabalho, no que diz respelto à verificação do envolvimento profissional da enfermeira em relação ao paciente. Das que em sua maloria se identificaram como chefes de unidade era de se esperar que fossem responsávels pela assistência de enfermagem prestadas a esses pacientes, no que deviam ser apolada pelas supervisoras. De forma significante, $11 \quad(78,5 \%)$ das enfermeiras perceblam a orientação so paciente diabético para o seu autoculdado, como parte integrante da assistência de enfermagem, e apenas 3 $(21,5 \%)$, assim não o consideravam. Dado o registro acima, era de se esperar que exstissem nessas unidades programas estabelecidos para tal orientação, porém, as respostas revelaram que 80mente $5(35,7 \%)$ possulam esses programas, o que não ocorria com as 9 respostas $(64,3 \%)$.

Ressalta-se a seguir que desses 5 programas, apenas um deles fol elaborado por enfermeira. Esse dado fica mais significativo quando se verifica que entre 14 enfermelras(os) apenas 1 assumiu a elaboração de programas de orientação para pacientes.

Observa-se empenho na avaliação da aprendizagem, quando $9(64,3 \%)$ das respostas afirmam haver uma avallação terminal após o processo ensino-aprendizagem. Essa informação revela que quatro enfermelras orientam e avaliam os pacientes eventualmente, ou participam de programas elaborados em conjunto com outros elementos da equipe de saúde. Dessa forma $5(35,7 \%)$ das enfermelras não estão integradas nessa atividade.

Quanto à metodologia utilizada para a avaliação da aprendizagem, apresentase defasada, por não haver registro dos resultados, o que possibilita reajustes no programa. Dos informantes que asseguram avaliar os resultados, $3(33,3 \%)$ os registram em fichas especials, e os demals $(66,7 \%)$ consideram as afirmativas verbais do paciente, de que haviam aprendido, sem uma devolução da aprendizagem prática ou resposta a testes escritos.

Diante do levantamento da situação em relação às enfermeiras, busca-se nas Informaçōes dos pacientes a descrição de como têm se considerado assistido nessa necessidade. Dos 36 respondentes, 20 $(55,5 \%)$ afirmaram que haviam recebido orlentação para o seu autoculdado, enquanto $16(44,5 \%)$ disseram que nunca haviam recebldo orientação. Verifica-se a seguir como as pacientes percebem a 
RAMOS, S.M. - Necessidade de orientaçāo à saúde do paciente diabético. Rev. Bras. Enf.; DF, 29 : 38-41, 1976.

atuação dos profissionais de saúde em relação a essa atividade de ensino, e constata-se que apenas 4 pacientes (11\%) foram orientados só por enfermeiras(os), $16(44,5 \%)$ receberam orientação dessas(es) e de outros profissionais, em trabalho de equipe e os demais 16 pacientes $(44,5 \%)$ não tiveram oportunidade de serem orientados.

\section{DISCUSSAO:}

Diante dos resultados acima descritos, percebe-se o quanto é válida a observação de BARNES (4) quando afirma que os elementos responsáveis pela assistêncla do paciente deveriam interessar-se em torná-lo auto-suficiente para o seu cuidado após a assistência prestada durante a internação, quando o paciente é considerado dependente de alguém da equipe que 0 assiste, para atividades perfeitamente passíveis de serem por ele assumidas. Essa afirmativa coincide com a atual filosofia da assistência de enfermagem que considera a individualidade do paciente, com suas potencialidades, seus conhecimentos e suas dificuldades. Por que estariam interessadas as enfermeiras em considerá-los incapazes de aprender a se cuidar, quando internados, e julgá-los capazes de assumir o auto-cuidado após a alta? Se elas informaram reconhecer a necessidade de ensinar aos pacientes e não a estão assumindo, revelam, na verdade a dificuldade que sentem na forma de desenvolver esse tipo de assistência.

\subsection{RECOMENDAÇOEES:}

\section{Aos Hospitais:}

Considerando-se que o ensino ao paciente diabético para o seu autocuidado assegura-lhe a saúde, recomenda-se que em todos os hospitais haja programas permanentes de orientação.

Considerando-se o registro da avaliação imprescindível à sequência da programação por outros elementos da equipe de saúde, recomenda-se que após cada aprendizagem se faça o devido registro no prontuário do paciente.

Considerando-se as possíveis modificaçōes que venham a ser feitas nos programas, recomenda-se o registro, em fichários, das facilidades e dificuldades sentidas no desenvolvimento de cada método e/ou técnica de ensino.

\section{As enfermeiras:}

Considerando-se a dificuldade revelada na assistência aos pacientes dependentes à nível de orientação, recomenda-se que participem de cursos que preparem profissionais da equipe de saúde para o ensino aos pacientes.

As escolas de Enfermagem:

Considerando-se que as enfermeiras não vêm participando efetivamente na orientação aos pacientes, para o seu autocuidado, recomenda-se que as estudantes de enfermagem, baseadas nos conhecimentos de Clínica Médica e de Didática planejem, desevolvam e avaliem a orientação a pacientes diabéticos.

\section{BIBLIOGRAFIA}

1. ARDUINO, F. - Diabetes Mellitus e suas complicaçōes. Editora Guanabara Koogan. Rio de Janeiro, 1973.

2. MENDES, I. A. C. - Observaçāo da Administraçāo de Insulina em pacientes diabéticos no domicilio. Tese de Mestrado em Enfermagem, Escola Ana Néri. Rìo de Janeiro, 1975.
3. RAMOS, S. M. - A aprendizagem do paciente diabético dependência de enfermagem a nivel de orientaçåo. Tese de Mestrado em Enfermagem, Escola de Enfermagem Ana Néri. Rio de Janeiro, 1975.

4. BARNES, E. - As relaçס̋es humanas no hospital. Iivraria Almedina. Coimbra, 1973. 